\title{
HISTÓRIA DA ESCRITA ATRAVÉS DE DESIGN EM MOVIMENTO
}




\title{
Caio Cortonesi
}

\section{HISTÓRIA DA ESCRITA ATRAVÉS DE DESIGN EM MOVIMENTO}

Design audiovisual como ferramenta para a educação em história da escrita

\author{
Relatório apresentado como parte integrante \\ do projeto de Diplomação em Programação Visual, \\ sob orientação do Prof. Luiz Fernando Las-Casas.
}

Departamento de Desenho Industrial

\section{UnB - Universidade de Brasília \\ 2008}


$\begin{array}{ll}\text { 1. RESUMO } & 4\end{array}$

2. INTRODUÇÃO $\mathbf{5}$

2. 1. Definindo o conteúdo: A história da escrita 5

2.2. Tipografia e a linha do tempo: Design audiovisual 6

2.3. Colocando o design em movimento 7

3. O DESIGN AUDIOVISUAL: UM BREVE HISTÓRICO 8

4. O PROJ ETO

4.1. Contextualização 11

4.2. Objetivos do projeto 12

5. METODOLOGIA

5.1. Pesquisa bibliográfica 14

5.2. Pesquisa Tecnológica 15

6. DESENVOLVIMENTO DO PROJ ETO 20

6.1. Primeira fase 21

6.2. Segunda fase 23

6.3. Terceira fase 24

6.4. Quarta fase 26

6.5. O produto final 26

$\begin{array}{ll}\text { 7. DISCUSSÃO E CONCLUSÃO } & 28\end{array}$

8. BIBLIOGRAFIA $\quad 30$

9. ANEXOS 32

7.1. Roteiro Narrativo 32 


\section{RESUMO}

O foco do proj eto exposto neste relatório é apresentar, através do uso do design como ferramenta atuante no espaço e no tempo, a história da escrita e da tipografia, assim como ilustrar a importância da escrita por tipos móveis para o design como hoje o conhecemos.

O objetivo secundário do projeto é apresentar uma linguagem que utiliza a união do design em movimento juntamente com recursos e técnicas audiovisuais diversas como ferramenta para a educação, com potencial de aplicação variada.

\section{Palavras-chave:}

História, escrita, tipografia, educação, design gráfico em movimento, cinedesign, audiovisual. 


\section{INTRODUÇÃO}

\subsection{Definindo o conteúdo: A história da escrita}

O desenvolvimento da palavra escrita é um subproduto da capacidade inerentemente humana de atribuir significados ao mundo. Possivelmente 0 passo mais relevante na diferenciação do Homo Sapiens dos demais primatas foi o desenvolvimento de uma linguagem complexa, que permitiu ao homem transmitir e trocar informações de forma mais eficiente com os demais, assim como para deixar o legado de suas descobertas para as futuras gerações.

As linguagens, em suas diversidades estimuladas pelo isolamento geográfico dos grupos e assentamentos humanos, encontravam-se confinadas nas mentes, nas entrelinhas das culturas que emergiam e se desenvolviam. Era uma questão de tempo até que o homem inventasse maneiras de eternizá-las, fosse em pedra, madeira, vegetal.

A escrita que hoje experimentamos como o alicerce do nosso conhecimento (e sem a qual nem mesmo este documento poderia estar sendo escrito ou interpretado) chegou às formas que atualmente conhecemos após milênios de modificações, adaptações, evolução e destruição. A relação deste processo com a nossa cultura e modo de vida é profunda, e por isso o estudo e compreensão deste processo é um assunto de interesse para designers, historiadores, antropólogos, artistas, sociólogos, lingüistas, entre diversos outros profissionais. Sem deixar de lado, naturalmente, as pessoas simplesmente movidas pela curiosidade e sede de conhecimento.

Para o profissional em formação, em nível introdutório, ou para os interessados no assunto, todos os recursos de enriquecimento possíveis neste campo de tanta relevância são importantes. Movido pelo desejo de dinamizar a apresentação de tal conhecimento, a proposta deste projeto é utilizar a linguagem audiovisual moderna para contar um pouco desta história. 


\subsection{Tipografia e a linha do tempo: Design audiovisual}

Quanto mais elevado o volume de informações que os indivíduos de uma sociedade precisam processar, mais complexo o relacionamento idéiaimagem-palavra se torna para acomodar as expectativas de leiturabilidade e comunicação entre grupos humanos.

Esta necessidade crescente foi o principal propulsor do design gráfico, uma área do conhecimento que busca unir os conceitos estéticos das belas artes à ciência da percepção, utilizando os ideais da comunicação para transmitir informações. 0 design é uma grande ferramenta para maximizar a capacidade evocativa de uma palavra, e é determinante no processo de se obter o efeito desejado no receptor.

Uma forma relativamente nova de comunicação verbal, legado do significado que o conceito de 'leitura' adquiriu para a sociedade moderna, é hoje presente em alguns dos meios de comunicação de maior alcance: 0 design em movimento (design cinético, design audiovisual, ou cinedesign).

Usando conceitos de ritmo, forma e cor, impulsionado pela dinâmica e freqüentemente em conjunto com áudio, o design audiovisual procura aumentar as capacidades linguísticas do design gráfico e da tipografia, atribuindo sentidos para as palavras e imagens que seriam impensáveis em ambientes estáticos. Hoje ele é grandemente presente no cotidiano de quem tem contato com mídias como televisão, computadores e cinema.

Utilizando a própria tipografia para ensinar sobre a história da tipografia, este projeto apresentará uma forma diferenciada de linguagem de ensino, usando uma ferramenta hoje usada principalmente pela publicidade, TV e cinema, para a educação. 


\subsection{Colocando o design em movimento}

A escolha deste mecanismo como a linguagem a ser adotada imprimiu a necessidade de uma metodologia diferenciada. Antes de dar início ao desenvolvimento do proj eto em si, três fases principais se mostraram marcantes.

Pesquisa bibliográfica

Voltada à definição do conteúdo sobre a história da tipografia a ser abordado no projeto. A pesquisa foi feita através de leituras de textos comentados, análise de opiniões divergentes entre especialistas e pesquisa informal com estudantes e profissionais da área de design acerca dos conteúdos que desejariam que houvesse no projeto.

Pesquisa tecnológica

Durante o período de definição do conteúdo, foi feita também uma pesquisa tecnológica. Esta pesquisa procurou levantar as características e limitações da linguagem escolhida, assim como a melhor maneira de desenvolver o proj eto diante do prazo. Esta pesquisa influenciou a escolha de plataforma, programas e fontes utilizadas para o desenvolvimento do projeto.

Desenvolvimento

A partir do roteiro definido na pesquisa bibliográfica, e respeitando os limites de tempo e ritmo delimitados na pesquisa tecnológica, foi feita a gravação da locução, e a partir desta, o desenvolvimento do produto final, conforme o processo especificado na seção "Produção". 


\section{O DESIGN AUDIOVISUAL: UM BREVE HISTÓRICO}

A tecnologia que possibilitou o avanço da arte audiovisual surgiu após uma longa evolução, iniciada com as imagens seqüenciais nas cavernas, passando pela fotografia e sua variante seqüencial, o cinema, trazendo gradativamente as formas digitais e interativas da atualidade.

0 tempo de leitura sempre foi um aspecto a ser considerado para a linguagem escrita, e isso provavelmente passou a ser mais reconhecido quando o texto começou a ser utilizado em conjunto com a imagem seqüencial, onde o texto narra ou complementa a idéia passada pelas imagens justapostas em conj unto.

A união de imagem e texto (desenvolvida enormemente com os hieróglifos egípcios cerca de 3200 anos a.C., além de outras culturas) mostrou-se uma ferramenta importante para a cultura humana, pois torna 0 texto mais dinâmico e reduz significativamente a necessidade de acumular informações em si, pois o conjunto torna-se mais comunicativo. Isso, além de reduzir o tempo exigido para a leitura, também criou novas formas de comunicação que iriam além da simples escrita.

Com o desenvolvimento do cinema, que em seus primórdios era desprovido de áudio, uma nova comunicação de massa surgiu. A ausência da capacidade de reproduzir sons ou vozes fazia com que o autor do filme precisasse de recursos para aumentar a capacidade descritiva ou narrativa do filme, que poderia ter o seu conteúdo confuso quando apresentado sem nenhum auxílio lingüístico. Com o tempo se passou a executar música ao vivo, durante uma exibição do filme, e os diretores tiveram a idéia de inserir cartelas de textos no filme.

Este texto, apesar de estático, lidava com novas variáveis que surgiam: Qual o tempo ideal para se exibir um quadro de texto sem se tornar arrastado ou rápido demais? Como pessoas iletradas ou de leitura lenta poderiam 
compreender o que se passava? Quais informações ou idéias são relevantes de serem comunicadas através de texto ao invés de imagens?

Com os avanços técnicos, passou a ser possível inserir texto diretamente sobre um filme sem interrompê-lo, e com o advento dos filmes falados, este texto passou a interagir potencialmente também com o som. Surgiram as legendas como traduções ou complementações da informação do áudio, e o ritmo com o qual os gráficos eram apresentados tornavam-se ainda mais relevantes na compreensão do filme.

No cinema, o design tipográfico ganhava cada vez mais importância, sendo utilizado como recurso narrativo ou informativo (no caso dos créditos) e com o surgimento e eventual popularização da TV isso foi transferido para a nova tecnologia. Isso contribuiu também para o que hoje vemos massivamente em efeitos de computação no cinema.
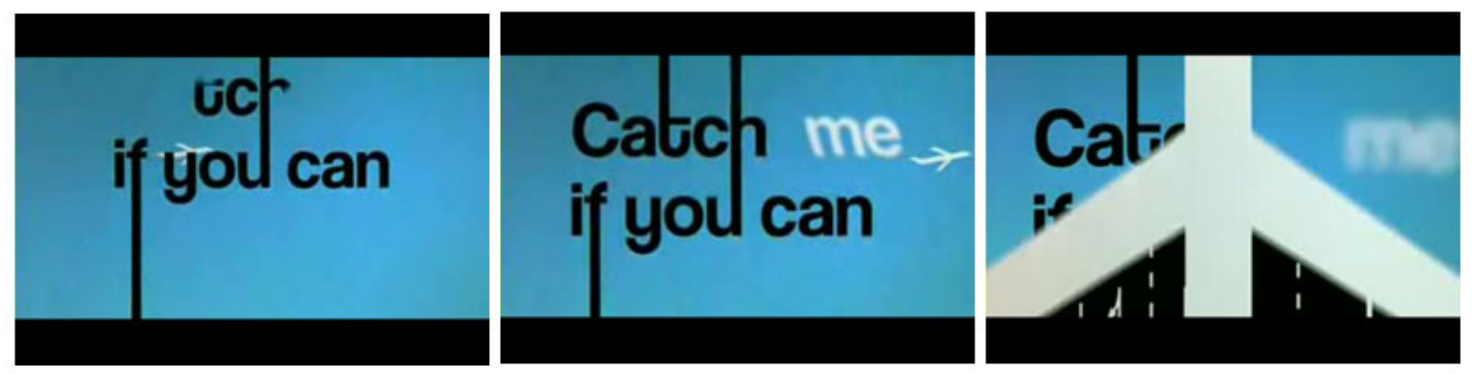

Fig. 1: Cenas da abertura do filme "Prenda-me se for capaz" (Catch me if you Can, 2002), exemplificando o uso de tipografia bidimensional como recurso ilustrativo no cinema da atualidade. Na seqüência pode-se notar a maneira como o texto é formado na linha do tempo. 0 processo total dura 6 segundos.

Tipograficamente, hoje, em tempos de televisão e design digital, temos uma flexibilidade enorme na manipulação do conteúdo gráfico em um material audiovisual. A forma com que um elemento gráfico é apresentado pode alterar totalmente o significado de uma obra. Filmes de ação exibirão textos surgindo e desaparecendo com grande rapidez; comerciais de TV darão 
destaque às informações importantes de um produto ou ao preço; os textos podem ajudar a narrar uma história sem necessidade de atores ou narração; os tipos ganham volume, textura, agem em um ambiente virtual como se realmente existissem; as possibilidades são inúmeras.

Diante desta realidade, a tarefa do designer é procurar a melhor maneira para que uma informação seja transmitida através de elementos gráficos ou textuais com eficiência, aproveitando um determinado conteúdo, espaço e tempo. 


\section{O PROJ ETO}

\section{1 . Contextualização}

É reconhecida a carência de recursos educacionais economicamente acessíveis para o ensino no Brasil, de diversas disciplinas, devido a fatores como o desnível econômico, baixo orçamento de instituições educacionais públicas, baixa assiduidade e altos níveis de repetência dos estudantes, assim como a freqüente não-adequação do material didático à realidade brasileira. Assim, muitos estudantes não se sentem estimulados a permanecer nas escolas e universidades, devido, entre outros motivos, à baixa atratividade dos obj etos de estudo e às condições precárias de infra-estrutura.

Este projeto buscará evidenciar a eficácia da utilização de material audiovisual na educação de jovens, inclusive no tocante do ensino de História. Diante desta proposta, estudantes alfabetizados em língua portuguesa de todas as classes sociais poderão usufruir dos benefícios informativos deste projeto, assim como instituições educacionais que desejem uma forma de baixo custo de lecionar de forma atrativa e introdutória.

Este projeto buscará representar um recurso de baixo custo e grande pregnância para o estudante, e poderá ser um atrativo considerável para instituições culturais ou de ensino como escolas ou museus. A proposta e sua linguagem, com eventuais modificações em seu conteúdo teórico, possuem potencial de serem utilizadas no ensino de virtualmente todas as áreas do conhecimento, com resultados promissores.

Os conceitos e teorias do design, hoj e comumente aplicados em publicações impressas ou digitais estáticas, são a ferramenta de maior valia para a qualidade da transmissão de informações entre as pessoas. No entanto, tais conceitos são freqüentemente negligenciados ou sub- 
aproveitados em mídias baseadas em movimento, levando a uma leiturabilidade e eficiência prejudicadas. Sendo assim, este projeto buscará também reafirmar a relevância da atividade do designer na hoje largamente indústria audiovisual.

\subsection{Objetivos do projeto}

O projeto consiste em uma peça de design em vídeo, com conteúdo em língua portuguesa, e dividido em 5 capítulos, que o usuário poderá selecionar para exibição através de uma interface simples (controle de DVD, tela touchscreen ou console).

Através do uso conj unto de tipografia, imagem e animação, o vídeo procurará expor de forma breve, sucinta e descontraída, a evolução do processo da escrita, desde seus primórdios pictográficos, passando pela evolução em alfabetos na antiguidade até a modernidade digital.

A utilização de áudio e narração complementará e enriquecerá a experiência do usuário, sempre em sincronia e inter-relação com o conteúdo apresentado tipograficamente no vídeo, obj etivando assim para garantir uma maior compatibilidade com ambientes onde não é possível a reprodução do áudio, assim como para deficientes auditivos.

0 público alvo é constituído de indivíduos que tenham interesse em aprender ou aprimorar o conhecimento sobre a escrita e tipografia, envolvidos ou não com a área profissional, assim como estudantes em estágio introdutório. Este público será composto principalmente, porém não exclusivamente, de jovens estudantes ou crianças em idade escolar.

0 enfoque de exibição do mesmo será em ambientes educativos ou residenciais, buscando a complementação do conhecimento em museus, exposições, ou em distribuição voltada à exibição residencial e em sala de aula. 
O principal embasamento teórico do vídeo serão conceitos de design, animação, tipografia e arquitetura de informação para uma maior acessibilidade ao público jovem e/ ou com necessidades especiais.
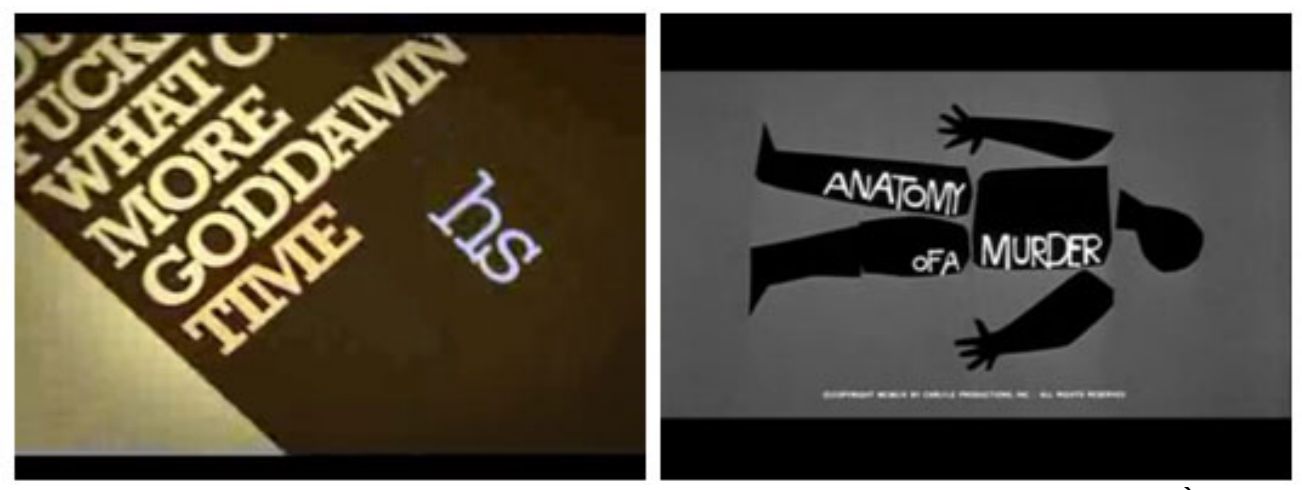

Fig. 2: Imagens que representam referências à proposta do proj eto. À esquerda: Tradução tipográfica de trecho de áudio extraído do filme "Pulp Fiction", feita por J arrett Moody, relevante pela forma com que o áudio interage com o texto, ditando seu ritmo. À direita: Cena da abertura do filme "Anatomia de um crime" (Anatomy of a Murder, 1959), feita por Saul Bass, um dos mais influentes designers de "Title Sequences" para cinema. 


\section{METODOLOGIA}

\section{1 . Pesquisa bibliográfica}

O conteúdo do projeto é voltado para a História da escrita, e para se definir o que seria explorado neste vasto universo, foi necessária uma devida pesquisa bibliográfica.

A História, mesmo sendo uma ciência em seu mais profundo significado, se caracteriza por ser uma disciplina na qual não existem consensos ou certezas absolutas. Os acontecimentos da antiguidade, amparados e estudados no dia de hoje através de resquícios documentais da época, sempre apresentam lacunas, pois é impossível se retratar toda uma época somente através de documentos. Assim, as contradições fazem parte de qualquer pesquisa histórica, afinal, tudo o que temos são teorias.

Para procurar amenizar esta questão profunda, que é intrínseca a toda pesquisa histórica, o roteiro do projeto foi montado a partir dos pontos convergentes de diversas fontes divergentes. 0 conteúdo também é apresentado de forma mais geral e leve, sem alegações muito marcantemente específicas ou absolutas, sempre com uma atmosfera de curiosidade e leveza.

Dois trabalhos fundamentais na elaboração do conteúdo foram a porção teórica do livro catalográfico "Type and Typography" (Ben Rosen), assim como o trabalho histórico sobre a escrita "Writing: The Story of Alphabets and Scripts" (J orges J ean), entre diversas outras obras detalhadas na seção Bibliografia.

A partir deste material, foi elaborado um roteiro inicial, focalizado primeiramente na idéia de expor todos os conceitos a serem abordados em 
uma linguagem, até então, ainda não adaptada à locução que seria a norteadora do ritmo e teor do vídeo.

Este texto inicial foi submetido à análise de estudantes de design e publicidade, ao professor orientador e a leigos, buscando manter a correção do conteúdo. No entanto a linguagem extremamente técnica exigiu uma reformulação do mesmo, buscando uma linguagem mais informal e focada em analogias.

Também foi feita uma significativa redução e corte de conteúdos de baixa relevância geral, para adaptação à tecnologia e ao prazo, assim como para não resultar em uma experiência demasiadamente longa.

\subsection{Pesquisa tecnológica}

Devido à especialidade do formato final escolhido para o proj eto, foi feita uma pesquisa analítica, buscando esquadrinhar as limitações tecnológicas mais importantes dentro desta mídia.

0 projeto é um vídeo em NTSC padrão comum (proporção largura $x$ altura 4:3), para compatibilidade com qualquer aparelho de DVD. Algumas características importantes deste formato são:

a. A taxa de frames ${ }^{1}$, de 29,97 por segundo (para efeito de ilustração, taxa de reprodução de frames num filme comum em película de cinema: 24 por segundo; vídeo PAL: 25 por segundo);

b. A resolução total da tela de 720 x 480 pixels, porém com uma área efetiva para televisores comuns $20 \%$ menor.

\footnotetext{
${ }^{1}$ Frame é o nome dado a cada quadro compõe um filme. A sensação de movimento em um filme é criada pela rápida mudança de frames, que são imagens estáticas.
} 


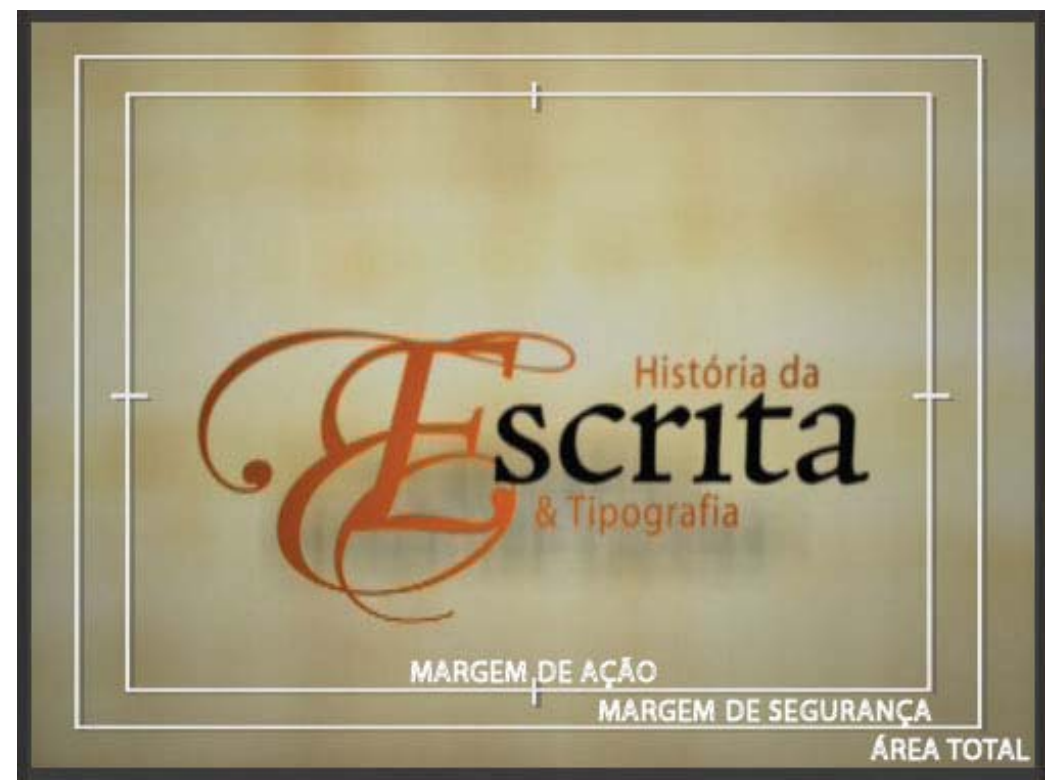

Fig. 3: Exemplo ilustrando a área total e suas margens de segurança. Em um computadores ou televisores digitais, a "área total" é visível. No entanto, em televisores de tubos de raios catódicos convencionais, somente a "margem de segurança" é visível.

c. Os pixels em um vídeo NTSC não são quadrados, como se poderia supor, mas levemente retangulares, com uma proporção de 1:0,9. Em televisores widescreen a diferença das proporções é ainda maior, de 1,6:0,9. Isso frequentemente leva a uma distorção (alargamento horizontal) do material exibido.

Televisores comuns também possuem outra peculiaridade: Os frames são apresentados entrelaçadamente. Ou seja, num televisor cada frame é apresentado em um padrão 'listrado' horizontalmente, metade das 'listras' correspondendo ao frame atual e a outra metade ao frame seguinte. Em computadores e mídias digitais, os frames são progressivos, ou seja, cada frame é um quadro inteiro, sem interferências dos seguintes. 

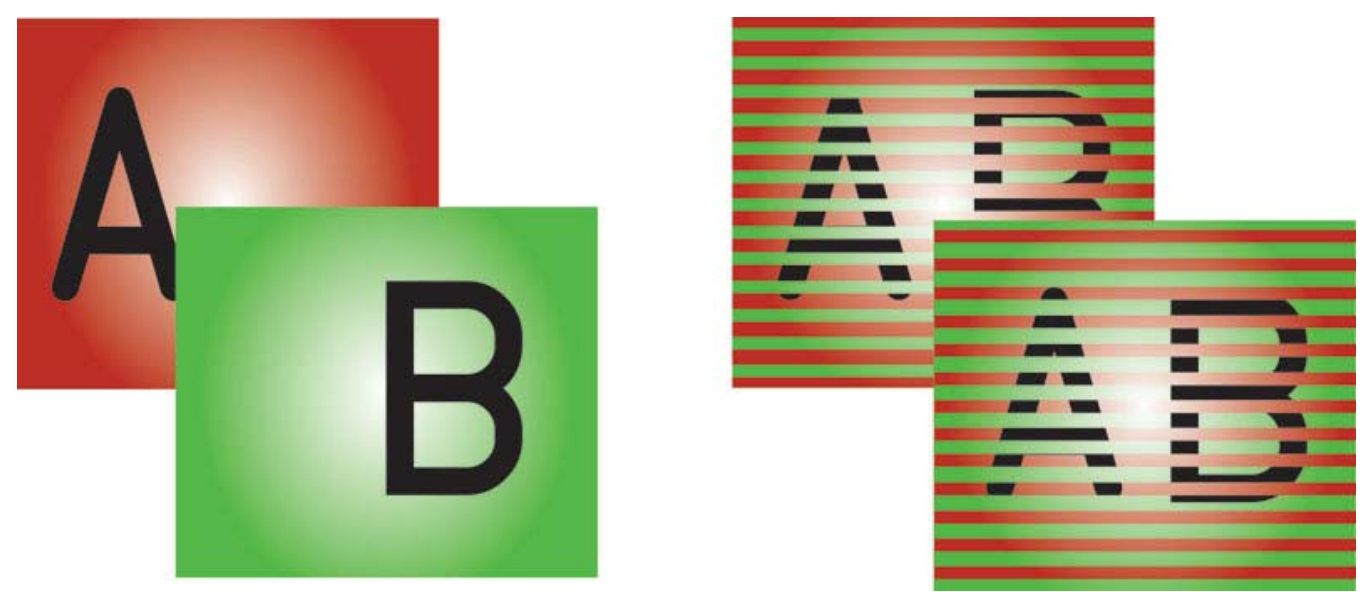

Fig. 4: Exemplo esquemático de frames progressivos (esquerda) e entrelaçados (direita).
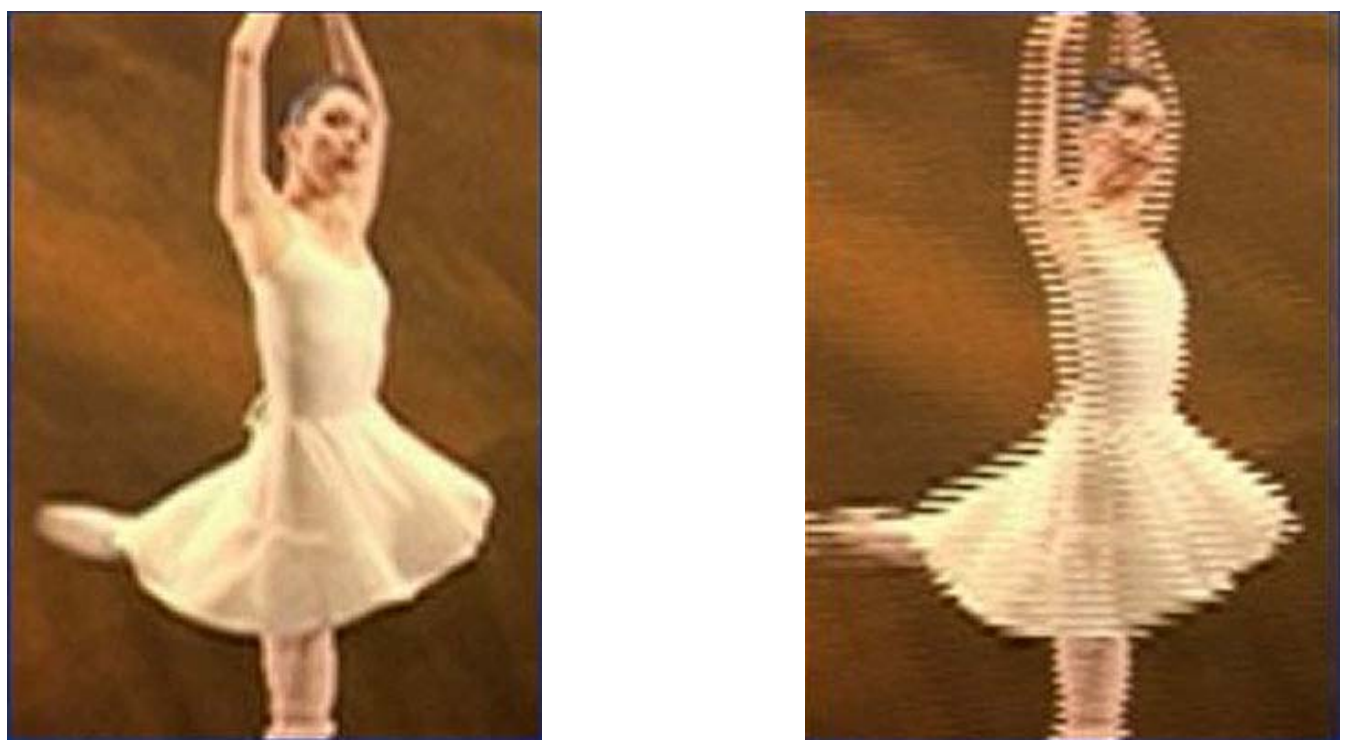

Fig. 5: Imagens em frames progressivos (esquerda) e entrelaçados (direita), vistos em um monitor progressivo. 
Assim, podemos esquadrinhar as restrições mais importantes para 0 projeto:

1. A superfície de leiaute é inexoravelmente horizontal e de forma e proporções físicas reais imutáveis;

2. É necessária uma margem de segurança considerável para as informações centrais, devido às divergências na capacidade de reprodução entre televisores, proj etores e monitores de vídeo;

3. A versão para DVD-vídeo deverá ser diferente da versão para computador, uma entrelaçada e outra progressiva (caso não seja feito desta forma, efeitos indesejáveis como instabilidade da imagem flicker - ou aparência listrada podem ocorrer);

4. A resolução de $720 \times 480$ pixels é relativamente pouco detalhada, especialmente em visores de alta resolução como monitores de computador ou televisores HD;

5. O menu do DVD apresenta limitações quanto à sua navegabilidade, já que o sistema de DVDs são suj eitos a 'loops', seus controles são necessariamente muito básicos e pode ocorrer lentidão em certas passagens;

6. Difusão via internet deverá ser feita através de versões menores e mais comprimidas do vídeo, já que o mesmo em sua qualidade máxima apresenta um tamanho muito acima do padrão atualmente aceitável para streaming ${ }^{2}$.

\footnotetext{
${ }^{2}$ Streaming (em tradução literal para o português: fluxo) é a transmissão sucessiva de dados através de um sistema de computadores - no caso, a internet. Em vídeo, o streaming funciona da seguinte forma: Enquanto o usuário assiste uma parte de um vídeo já recebido, o sistema recebe dados relativos ao restante, e o armazena. Assim, de acordo com a velocidade de conexão do usuário, pode-se assistir a um filme de alta qualidade pela internet, em tempo real ou com uma breve espera.
} 
Apesar das restrições, a escolha da tecnologia de vídeo (padrão NTSC digital) também apresenta vantagens, especialmente sobre as tecnologias Flash ou vídeo de alta definição (HD):

1. Alta compatibilidade;

2. Flexibilidade por trabal har com imagens rasterizadas, e não vetorizadas. Isso permite o uso de animações e gráficos complexos;

3. Um DVD, além de ser uma mídia acessível, possui espaço o suficiente para o vídeo sem perda de qualidade por compressão;

4. Alta velocidade de leitura. 


\section{DESENVOLVIMENTO DO PROJ ETO}

Para facilitar a administração e a exposição do cronograma do projeto, o desenvolvimento do mesmo foi dividido em quatro grandes fases:

Primeira fase

Corresponde à definição do conteúdo exato a ser lecionado através do projeto, através de pesquisa bibliográfica, pesquisa com estudantes e com a consultoria de educadores da área e profissionais iniciantes. Nesta fase também foi definido o texto final para a gravação da locução, já em linguagem informal.

Segunda fase

Criação de storyboard textual a partir do texto estabelecido na primeira fase, com idéias iniciais de analogias estéticas para o projeto. Nesta fase também foi gravado o áudio da locução, feitos cortes adicionais no conteúdo do roteiro buscando otimizar o tempo de execução.

\section{Terceira fase}

Desenvolvimento do projeto de vídeo, utilizando o áudio da locução como referência rítmica e o texto elaborado. Inserção da trilha sonora e efeitos de áudio adicionais.

Quarta fase

Finalização dos trabalhos de vídeo com a criação da identidade dos menus interativos e implementação dos mesmos. 


\section{1 . Primeira fase}

Nesta fase foi feita uma pesquisa histórica, buscando definir o conteúdo ministrado no projeto, utilizando como base principal textos comentados.

A principal referência para a porção voltada à história da escrita foi 0 sintético livro de J orges J ean, "Writing: The Story of Alphabets and Scripts". (1987). Este livro apresenta um apanhado geral sobre a história da escrita na antiguidade até a criação dos alfabeto latino. Depois, o mesmo segue, porém sem tanta ênfase, até a tipografia.

Nesta fase, uma observação importante foi a detecção e comparação de pontos conflituosos entre as bibliografias, devido à natureza predominantemente teórica da história enquanto área do conhecimento. Portanto, outras fontes foram utilizadas como filtros de pontos ainda não unânimes entre os especialistas. Os principais foram "A Palavra Escrita" de Wilson Martins (1972) e o artigo de Luiz Fernando Las-Casas, “Uma Pequena História da Tipografia" (2006).

Para a porção voltada à história da tipografia, as principais fontes foram o livro-catálogo de Ben Rosen, "Type and Typography" (1963), que tem um belo apanhado histórico sobre a história tanto da escrita quando da tipografia.

O livro de Marshall McLuhan, "A Galáxia de Gutemberg” (1972) contribuiu com informações sobre a percepção da escrita na antiguidade, assim como o impacto da escrita com tipos móveis na sociedade.

A partir destas fontes, delineou-se um texto narrativo englobando 0 assunto a ser tratado. 0 conteúdo foi dividido em cinco partes, que correspondem aos capítulos no produto final: 


\section{Introdução}

Panorama geral sobre a importância do design tipográfico na atualidade, a importância da atividade do designer na mesma, e os fatores intelectuais e culturais que originaram a escrita;

2. Escrita como Atividade

O desenvolvimento da escrita como atividade espiritual e social em suas diversas origens através das eras, o cruzamento das influências culturais na antiguidade e idade média, os primórdios da caligrafia no oriente e ocidente;

3. Escrita como Forma

O desenvolvimento do alfabeto latino, sua evolução e ramificações estilísticas, a relação com o clero e nobreza, grupos tipográficos básicos, até a criação da imprensa;

4. Tipos Móveis

História da impressão por tipos móveis, origens e desenvolvimento, assim como uma explicação simplificada do seu funcionamento e processos de fabricação;

5. Hoje em Dia O legado dos tipos móveis na era digital, a importância social e artística da tipografia na atualidade, o futuro da atividade do designer e considerações de encerramento.

0 roteiro com o texto da narração encontra-se em anexo.

0 texto, até este ponto, ainda se manteve com uma linguagem mais técnica e detalhista. A partir daí, foi iniciado um trabalho de eliminação de 
informações excessivas e linguagem rebuscada, buscando aproximar de uma informalidade mais típica em textos falados.

\subsection{Segunda fase}

A partir do texto desenvolvido na primeira fase, foi elaborado um storyboard textual, documentando apenas o surgimento inicial das idéias gráficas que seriam utilizadas em cada trecho do projeto.

0 passo seguinte foi o contato de um profissional para executar a locução, e a gravação da mesma.

Este passo é extremamente importante, pois o ritmo do vídeo será baseado principalmente na locução. Por isso, buscou-se manter uma inflexão pausada, porém com um andamento próximo ao da fala informal para manter a dinâmica na transmissão do conteúdo. Buscou-se um tom de voz escolhido informal, visando assim uma maior comunicatividade e identificação com o usuário, porém grave e seguro, para evocar credibilidade.

Neste ponto, a duração aproximada do produto final ficou mais clara, e seria algo entre 8 e 12 minutos de duração, de acordo com aj ustes de conteúdo e ritmo a serem feitos posteriormente.
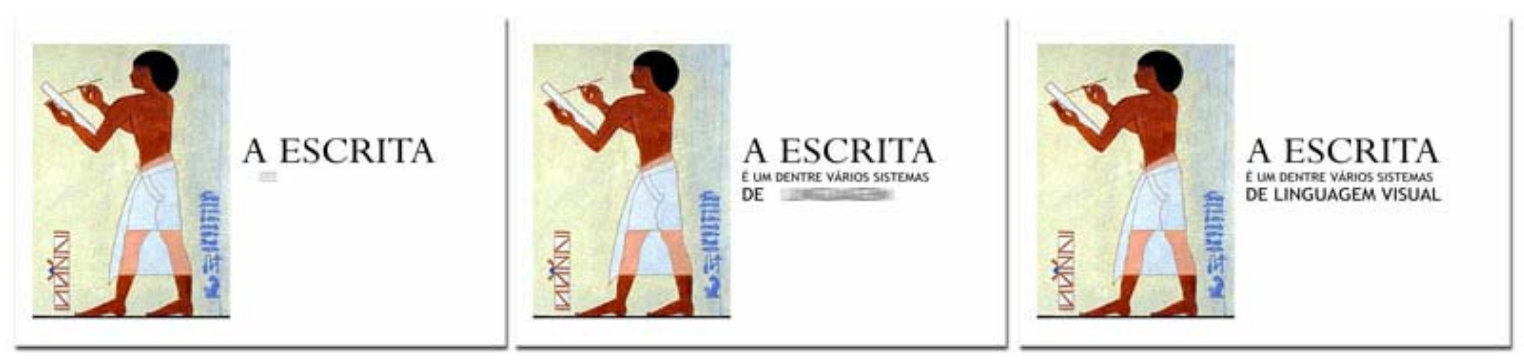

Fig. 6: Seqüência do projeto, ilustrando uma das técnicas de formação de frases, palavra por palavra, no ritmo da locução. É significativo para facilitar a compreensão que se haja algum tempo (aproximadamente 1 segundo) de exposição do texto completo. Por isso, nesse tipo de aparição o texto conclui sua formação um pouco antes da locução finalizar. 


\section{3 . Terceira fase}

Com o texto e a locução em mãos, foram iniciados os trabalhos de design.

Graficamente buscou-se uma identidade sóbria e funcional, porém sem se apegar a famílias tipográficas, já que o pluralismo estético é possivelmente um dos temas principais do filme.

Cores, texturas e formas foram usadas em conjunto com imagens procurando evocar a idéia de forma eficiente. Neste processo, onde em uma metodologia de design convencional seria a geração e seleção de alternativas, ocorreu de forma comparativamente muito mais ágil e informal, devido à freqüência com que tais escolhas precisavam ser feitas.

A principal analogia e inspiração buscada para as escolhas estéticas do vídeo foram a de uma revista em movimento. O leiaute muda sua forma a cada "página", a cada bloco de texto, buscando exemplificar o sentido do seu conteúdo de uma forma análoga. Conforme o ritmo do texto aumenta ou diminui, o andamento da exposição gráfica dinamiza-se da mesma forma.

A preferência pelo uso de imagens estáticas ao invés de footage em vídeo foi uma escolha consciente, em harmonia com a proposta do projeto ser uma 'revista em movimento'. Material fotográfico de qualidade relacionado ao tema também mostrou-se significativamente mais acessível do que material filmado.

Buscando uma aparência com influências cinematográficas, almejada para se obter um resultado mais envolvente para o usuário, o software de computador escolhido para a execução do projeto foi o After Effects (Adobe), um programa de arte-finalização, utilizado de forma profissional em cinema e vídeo. Este software opera basicamente com composição de vídeo, de forma similar a um editor de imagens, porém em uma timeline, (linha do tempo) com possibilidades de animação e utilização de elementos tridimensionais. 
Para ilustrações e edições adicionais, foram utilizados em conjunto com 0 After Effects, o software de desenho vetorial Illustrator (Adobe), o editor de imagens Photoshop (Adobe), assim como o editor de vídeo não-linear Premiére (Adobe) para a sincronização do áudio e edição final do material bruto em vídeo.

0 ajuste da sincronia entre vídeo e áudio foi programado conforme 0 desenvolvimento do vídeo seguia, porém edições adicionais de audio mostraram-se necessárias para uma melhor sincronia, e foram feitas com 0 auxílio do software de áudio Nuendo (Steinberg).

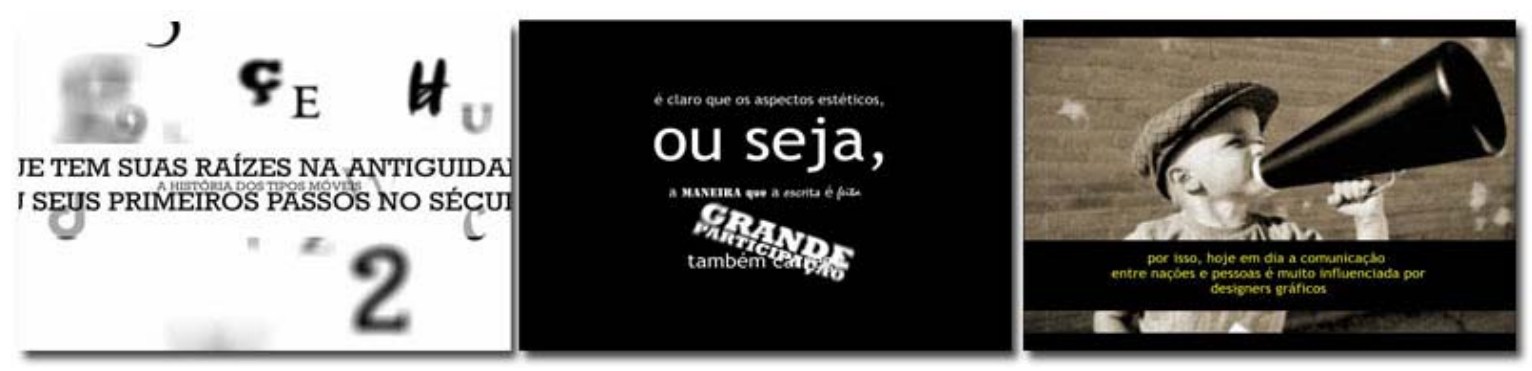

Fig. 7: Cenas do projeto, ilustrando algumas das variedades visuais exploradas, sempre buscando a melhor analogia na representação do conteúdo. Em vez de uma identidade fixa, foi escolhida uma identidade cambiável, sempre procurando manter uma estética e funcionalidade adequadas enquanto explora os recursos de cor e forma.
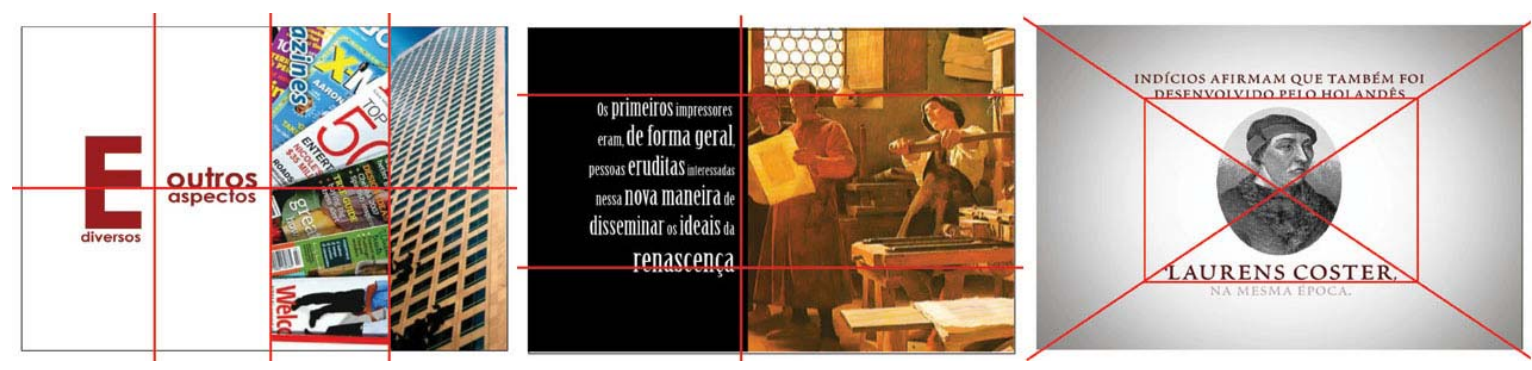

Fig. 8: Exemplos de alguns 'grids' de leiautes utilizados no projeto, ilustrando a variedade explorada, devido à necessidade de se manter o material dinâmico. 


\section{4 . Quarta fase}

Com a conclusão do material em vídeo, dividido em capítulos, viu-se necessário o desenvolvimento de um sistema para permitir ao usuário manipular o acesso ao conteúdo diversificado.

0 mecanismo escolhido preliminarmente foi o da tecnologia para menus de DVD, devido a sua acessibilidade de criação e versatilidade de utilização, além de sua compatibilidade com aparelhos de DVD comuns.

Procurando manter uma funcionalidade simples e intuitiva, e devido ao fato de no projeto inexistirem legendas (convencionais, do tipo utilizadas em filmes de DVD) ou trilhas de áudio adicionais, foi feita apenas uma tela de menu, acessível no momento em que se insere o DVD ou pressionando-se a tela "Title" do controle do aparelho.

0 menu foi desenvolvido em sua forma e funcionalidade com os softwares Encore DVD (Adobe) e Photoshop (Adobe).

\section{5 . 0 produto final}

Após as quatro fases, o produto final é um DVD-vídeo que pode ser executado em computadores ou aparelhos de DVD convencionais, adaptados para ambientes públicos interativos ou colocado em repetição em feiras ou eventos.

A implantação inicial do produto será em um formato em DVD, acessível a instituições educacionais que tenha interesse em disponibilizar o material para seus estudantes ou usuários. No entanto, este projeto possibilita futuras implantações e expansões.

Futuros desenvolvimentos possíveis para o projeto seriam:

a. A teledifusão via TV; 
b. Acesso em Streaming ou Download pela internet em sites educacionais, públicos ou feitos exclusivamente para este fim;

c. A comercialização do produto em formato de DVD possivelmente com material textual relativo ao assunto, ou mesmo com revistas que abordem temas similares em matérias;

d. A expansão e incremento do conteúdo e linguagem do vídeo, criando assim um filme de duração mais longa, ou mesmo uma série;

e. A comercialização do produto enquanto formato, com possibilidade de adaptação de seu conteúdo para o ensino de diversos temas relacionados ou não ao design gráfico. 


\section{DISCUSSÃO E CONCLUSÃO}

Os conceitos de funcionalidade, estética e metodologia típicos do design em poucos momentos eram imaginados como parte do processo de criação de gráficos para cinema e vídeo, até bem pouco tempo atrás. 0 campo audiovisual é raramente citado como parte do currículo de cursos de design, e geralmente é associado muito mais com a atividade de edição de vídeo do que com o design gráfico propriamente dito.

Hoje, com a acessibilidade das ferramentas de criação, e com a internet como um grande meio de propagação audiovisual, o design em movimento tem se tornado uma parte importante tanto no cinema (em sua concepção mais simples, de imagem em movimento) como arte quanto como funcionalidade.

Mesmo com poucos recursos econômicos, artistas independentes hoje podem criar filmes relevantes e de grande impacto, utilizando-se apenas de fotografia, audio e computação gráfica - que hoje tem ferramentas muito mais baratas e acessíveis do que há meros 5 anos atrás. 0 potencial experimental do design gráfico em movimento apresenta hoj e uma gama de possibilidades inexploradas, muito maior do que era possível na época dos primórdios dos grafismos no cinema (na década de 20, com os trabalhos de artistas/ designers como Hans Richter, Man Ray e Saul Bass).

Em consonância com esta realidade, a proposta deste projeto é de apresentar e desenvolver o potencial do design em movimento em um ambiente acadêmico, voltado para o benefício do próprio meio educacional, tanto pela perspectiva apresentada quando na criação de um produto com potencial de uso efetivo dentro do próprio curso de programação visual.

$\mathrm{O}$ design é sobretudo uma área do conhecimento multidisciplinar, e quanto maior proximidade e interação entre o conhecimento do designer e 0 
do diretor, do músico, do professor, maior o enriquecimento de todos os campos.

A busca de um paradigma que leve a uma nova e mais clara compreensão do processo do design dentro do ambiente audiovisual foi o combustível desta proposta, e com este projeto busco não apenas atender aos objetivos específicos ao projeto - que é de oferecer uma nova ferramenta de baixo custo para o ensino - mas também de contribuir na atual evolução do pensamento do designer brasileiro para além da programação visual pura e simplesmente estática. 


\section{BIBLIOGRAFIA}

ARAGÃO, Isabella Ribeiro. A dimensão gráfica do cinema: Uma proposta de classificação de suas configurações, Universidade Federal de Pernambuco, 2006.

BRINGHURST, Robert. Elementos do Estilo Tipográfico. Versão 3.0. São Paulo, Cosac Naify, 2005.

J EAN, J orges. Writing: The Story of Alphabets and Scripts. New York, Harry N. Abrams Inc. Publishers, Série Discoveries, 1987.

LAS CASAS, Luiz Fernando. Artigo Uma Pequena História da Tipografia.

LAS CASAS, Luiz Fernando. Cinedesign: Typography and Graphic Design in Motion Pictures - The AMPAS Awards, New York University, 2006.

MARTINS, Wilson. A Palavra Escrita. São Paulo, Editora Anhembi Ltda., 1957.

MCLUHAN, Marshall. A Galáxia de Gutemberg. São Paulo, Editora Nacional - USP, 1972.

ROSEN, Ben. Type and Typography. Reinhold Pub Corp, 1963.

RUDGLEY, Richard. The Lost Civilizations of the Stone Age. New York, Simon \& Schuster, 2000. Pg. 48-57. 
TIETZMANN, Roberto. Uma proposta de taxonomia de créditos de abertura cinematográficos, Universidade Federal de Pernambuco, 2006.

VINCENT, Charles C., COLE, Ariane Daniela, SCHINCARIOL, Zuleica. Design em Movimento - um Original Digital?, Universidade Presbiteriana Mackenzie, 2006. 


\section{ANEXO}

\section{1. Roteiro Narrativo}

\section{INTRODUÇÃO}

Informar, armazenar, explicar, persuadir: Necessidades fundamentais para quase todas as sociedades de hoje. A evolução da civilização foi calcada no alfabeto e na escrita, e nossa história somente passou a ser documentada quando nossos ancestrais passaram a utilizar estas ferramentas.

A escrita é um dentre vários sistemas de linguagem visual, como o desenho, a mímica, os códigos luminosos, gestos, entre muitas outras. No entanto, ela é provavelmente o meio mais perfeito e menos ambíguo de armazenar e transferir informações entre as pessoas desde que nossos ancestrais passaram a usá-la, há mais de 6.000 anos atrás.

É claro que os aspectos estéticos, ou seja, a maneira que a escrita é feita, também carrega uma grande participação neste processo. Por isso, hoje em dia, a comunicação entre as nações e pessoas é muito influenciada por designers gráficos, que usam toda sua técnica, inventividade e um pouco de loucura, para transmitir conhecimento de forma bela e eficiente.

Para entender melhor a importância do design das letras para a comunicação, vejamos a história dos tipos móveis, que tem suas raízes na antiguidade e deu seus primeiros passos no século quinze.

\section{ESCRITA COMO ATIVIDADE}

A escrita surgiu com a necessidade de se armazenar informações de forma mais confiável do que por via oral. Ainda nas cavernas, há quase 7.000 anos, algumas pessoas começaram a registrar acontecimentos especiais, com um caráter ritualístico e espiritual. Esses acontecimentos eram as caçadas, a chuva, o nascer do sol, a abundância ou escassez de comida. Com esses registros, fomos aprendendo o poder comunicativo das imagens, e a capacidade delas evocarem idéias e sensações. 
Conforme avançamos no tempo, chegamos, 5.000 anos atrás, à escrita cuneiforme na mesopotâmia (onde hoje fica o Iraque). Representando figuras rudimentares através de ferramentas pressionadas contra argila ou cravadas nas pedras, ela começou a ser usada para contar quantidades de coisas, assim como para indicar o que estava sendo contado.

Enquanto isso, na África, os egípcios cortavam na pedra e madeira figuras decorativas que representavam não somente formas, mas também partes de palavras faladas (como as nossas sílabas) e idéias. 0 mais interessante é que combinações de figuras formavam ainda outras idéias, sendo assim um dos primeiros alfabetos.

No próprio Egito também se passou a escrever sobre papiro, um ancestral do papel que era feito folhas da planta de mesmo nome entrelaçadas e coladas. Para escrever no papiro, eles utilizavam cálamos, segmentos finos de junco embebidos em tinta. O cálamo desenhava com contrastes de fino e grosso bem característicos, que se tornaram fundamentais no desenvolvimento da caligrafia e, mais tarde, da tipografia.

1.500 anos depois, os fenícios deram mais um passo a frente, desenvolvendo um sistema fonético, ou seja, baseado na fala. Esta foi a raiz da escrita dos gregos, que adicionaram vogais ao alfabeto fenício, influenciando a escrita latina, que é a que usamos hoje na língua portuguesa. O alfabeto fenício também inspirou as línguas semíticas e árabes, que continuaram baseados somente nas consoantes, criando alfabetos que hoje chamamos de "Abjads".

Enquanto isto, em terras longínquas, as coisas também se desenvolviam, mas de formas diferentes. Os chineses criaram uma escrita não alfabética, mas baseada em símbolos. Nesta escrita, ocorria uma forma diferente de interação entre idéia e símbolo. Por exemplo: Assim como o tom e a força que falamos dá diversos significados para uma palavra, o mesmo acontece na palavra escrita chinesa.

Como a arte da escrita acumulava milhares de palavras e regras que exigiam anos de estudo para serem dominadas, o difusor das idéias não era o homem comum, mas aquele que detinha o poder e o conhecimento: A nobreza e a igreja. A própria palavra "Caligrafia", do grego kalos - que significa "belo" - representa a nobreza e especialidade da atividade. 


\section{ESCRITA COMO FORMA - A FORMA DA ESCRITA}

As formas a partir das quais nossas letras foram criadas começaram com a escrita grega, que é lida da esquerda para a direita, como a nossa. As letras são caracterizadas por linhas retas, curvas e ângulos, em formas harmoniosas.

Em 114 d.C., na Coluna de Trajano, construída em honra aos feitos do imperador de mesmo nome, foi inscrito um texto que mudaria para sempre as letras. Ele exibia formas emprestadas da Grécia clássica, mas de maneira matematicamente proporcional, adquirindo uma nobreza que, além de representar a força do império romano, tornou-se o principal modelo para a escrita ocidental.

Conforme o tempo passava, o aspecto da escrita tomava diferentes rumos. Os romanos da época imitavam nas pedras a escrita de penas em papiros, e a escrita em papiros evoluía, criando cinco formas principais de letras latinas: As quadratas, com letras quadradas; as rústicas, com letras condensadas, ou seja, menos largas que as quadratas; as unciais, mais arredondadas e que imitavam as formas criadas em um desenho com bico de pena; as semi-unciais, um estilo mais relaxado e exagerado das unciais; e as cursivas, que surgiram conforme as pessoas escreviam de forma mais apressada. Alguns pesquisadores até dizem que a escrita do ocidente desenvolveu-se por 'deterioração' ou 'adaptação', já que, na pressa de escrever, os escribas foram modificando cada letra ao adaptá-las à rapidez, à facilidade de desenhar com as mãos e com o cálamo.

Entre os séculos V e IX, diversos novos estilos emergiram, entre eles era a Round Hand, carregada de ornamentos e muito ilustrativa. Também surgiram as minúsculas carolíngias, uma forma miúda de escrever criada pela necessidade de um abade chamado Charlemagne transcrever e padronizar centenas de textos antigos escritos de formas diferentes. Essa escrita miúda hoje é o que chamamos de letras minúsculas. Com as influências étnicas de toda a Europa, surgiam também as Escritas Regionais, influenciadas pelas características da escrita de cada região.

Nos séculos XII e XIII a escrita se dividia ainda mais: Os textos seculares, ou seja, não ligados à igreja, já usavam letras inspiradas nas capitulares romanas. A igreja, procurando uma forma de 'elitizar' seus escritos, desenvolveu a forma gótica, 
caracterizada por letras condensadas, angulares, escuras e bem complicadas de serem lidas. Assim, os diversos estilos caligráficos agrupavam-se ao redor de dois grupos: As romanas antigas, usadas pelos seculares, e as góticas, usadas pela igreja.

Foi nesse ambiente efervescente que a impressão com tipos móveis tornava-se uma realidade.

\section{TIPOS MÓVEIS}

O ourives alemão J ohann Gensfleish zum Gutenberg é geralmente chamado de 'pai da imprensa', mas os fundamentos da escrita por tipos móveis já eram utilizados séculos antes pelos chineses e coreanos. Existem indícios que afirmam que a tecnologia também foi desenvolvida pelo holandês Laurens J anszoon Coster na mesma época.

A idéia é bem simples: As letras são pré-moldadas em pequenas peças de madeira ou metal e colocadas sobre uma plataforma. Os espaços entre palavras são feitos por peças sem relevo, e desenhos também podem ser inseridos. As peças são presas em eixos que garantem que elas fiquem alinhadas umas com as outras, e depois do texto estar totalmente formado na plataforma, eles são presos no lugar. Elas então são cobertas com tinta, e o papel é pressionado sobre as pecinhas. É como um grande carimbo, porém totalmente modular.

Como os primeiros tipos móveis eram fabricados à mão, eles eram feitos a partir de moldes, pois para uma coleção eram necessárias várias cópias de uma mesma letra, e várias coleções iguais eram feitas para impressores diferentes. 0 escultor, que às vezes era o próprio criador da coleção, cortava a forma externa da letra, letra por letra, e o espaço no meio de letras como as minúsculas " $e$ ", " $g$ " e "o" eram então furados no meio. Com a invenção do pantógrafo no século XVII (1603), os tipos passaram a ser feitos de forma mais mecânica, agilizando e aumentando a precisão do processo, e aliviando também o trabalho lento e repetitivo dos escultores.

Os primeiros impressores eram, de forma geral, pessoas eruditas, interessadas nessa nova maneira de disseminar os ideais da renascença. Eles buscavam, a princípio, dar uma aparência de manuscrito a seus livros, mas conforme a arte evoluía, formas inéditas de facilitar a leitura foram surgindo. Novas formas às letras surgiram graças a tipógrafos como J ohann Fust, Adolf Rusch, Nicholas J enson, Aldus Manutius, Claude 
Garamond, William Caxton, entre muitos outros que surgiam rapidamente, com contribuições importantes à nova arte que se misturava com ciência.

\section{HOJ E EM DIA (CONCLUSÃO)}

Originalmente criada como uma forma de acelerar a cópia de escritos, a impressão também se tornou uma ferramenta de inclusão social e popularização da informação. Hoje, o desenho de tipos é fundamental para jornais, livros, revistas, televisão, embalagens, indústria, arquitetura, e diversos outros aspectos da nossa vida cotidiana.

Após as duas grandes guerras, os processos fotográficos, avanços na fabricação de papel e tinta e o surgimento do computador fizeram com que as tecnologias convergissem. Isso fez o processo de impressão por tipos móveis reduzir sua importância como processo industrial de reprodução gráfica, mas suas teorias e técnicas são até hoje parte integral no desenvolvimento da linguagem tipográfica.

Embora ainda existam muitos analfabetos pelo mundo, ser capaz de ler é fundamental para o bem estar social, cultural e material de todo cidadão. Hoje, a atividade tipográfica, que antigamente foi altamente especializada e elitista, teve 0 seu acesso facilitado ao público leigo graças ao computador pessoal.

Com a difusão de ambientes eletrônicos para a transmissão de informações como telas de TV e computadores, assim como com a impressão baseada em informação digital, novas famílias de alfabetos surgem diariamente, aproveitando a flexibilidade oferecida por pixels, ao invés de peças de madeira ou metal.

Algumas fontes foram criadas especificamente para o uso em computadores, enquanto centenas de outras foram desenvolvidas buscando adicionar expressividade e simbolismo às letras. Sem contar nas versões atuais das famílias clássicas, que se mantém fiéis ao seu propósito de oferecerem uma melhor leitura quando impressas em papel.

Ao longo de mais de 7.000 anos, as idéias, ações e percepções humanas se transformaram em linguagem, e a linguagem, em escrita. Com o crescimento demográfico e cultural da humanidade, a escrita passou a ter uma importância social e 
política sem igual, e sua democratização fez necessário o desenvolvimento de novas formas de distribuir o conhecimento.

O bom uso das ferramentas e recursos relativos à maneira de se escrever pode determinar se uma informação será bem transmitida, um cartaz efetivo, uma publicação aceita, uma revista vendida, um website funcional, e muito mais... 